\title{
Effects of distillers dried grains with solubles and added fat fed immediately before slaughter on growth performance and carcass characteristics of finishing pigs ${ }^{1}$
}

\author{
K. F. Coble,* J. M. DeRouchey,* M. D. Tokach,* S. S. Dritz, $\uparrow$ R. D. Goodband*2, and J. C. Woodworth* \\ *Department of Animal Sciences and Industry, College of Agriculture and $\dagger$ Department of Diagnostic \\ Medicine/Pathobiology, College of Veterinary Medicine, Kansas State University, Manhattan 66506-0201
}

\begin{abstract}
The addition of dietary fat has been shown to increase HCW and carcass yield in pigs fed low-fiber corn-soy diets; however, data on added fat in high-fiber, low-energy diets is less available. Therefore, the potential for dietary fat to ameliorate the negative effect high-fiber diets have on carcass yield during the last $3 \mathrm{wk}$ before slaughter is of high importance. This experiment was conducted to determine the interactive effects of $30 \%$ distillers dried grains with solubles (DDGS) and 5\% added fat fed before slaughter on growth performance and carcass characteristics. A total of 1,258 pigs in 2 groups (initially $105.8 \pm 0.1$ $\mathrm{kg}$ BW; group 1 PIC $337 \times 1$, 050 ; group 2 PIC $327 \times$ 1,050 ) were used in a 20-d experiment. All pigs were fed a common diet with 30\% DDGS until $20 \mathrm{~d}$ before slaughter. Then, all pens were weighed and allotted to treatments with 20 replicate pens per treatment. Dietary treatments were arranged in a $2 \times 2$ factorial with 2 diet types (corn-soybean meal-based with or without
\end{abstract}

$30 \%$ DDGS) and added fat ( 0 or 5\%; group $1=$ tallow; group $2=$ choice white grease). Diets were formulated to a constant standardized ileal digestible Lys:NE ratio. There were no treatment $\times$ group interactions for any response criteria. Thus, data for the 2 groups were combined for analysis. Overall, there was a tendency for a diet type $\times$ added fat interaction for ADG $(P=0.054)$, whereas this was significant for G:F $(P=0.008)$. This was a result of $5 \%$ added fat increasing $\mathrm{ADG}$ and $\mathrm{G}: \mathrm{F}$ to a greater magnitude for pigs fed the diet containing 30\% DDGS (8.6 and $10.4 \%$, respectively) than for pigs fed the corn-soy diet (2.0 and 2.9\%, respectively). Although diet type did not affect final live BW, pigs fed the diet containing DDGS had decreased HCW and carcass yield $(P<0.05)$. Adding $5 \%$ fat did not affect carcass yield. In conclusion, adding $5 \%$ fat to finishing pig diets containing 30\% DDGS approximately $20 \mathrm{~d}$ before slaughter improved ADG and G:F but did not overcome the reduction in carcass yield from feeding DDGS.

Key words: fat, fiber, finishing pigs, withdrawal, yield

(C) 2017 American Society of Animal Science. All rights reserved.

J. Anim. Sci. 2017.95:270-278 doi:10.2527/jas2016.0679

\section{INTRODUCTION}

Feeding pigs high-fiber ingredients, such as distillers dried grains with solubles (DDGS) and wheat middlings, throughout the finishing period negatively affects HCW and carcass yield (Whitney et al., 2006; Salyer et al., 2012). Turlington (1984) determined that the reduction in carcass yield from feeding high-fiber ingredients resulted from an increase in gut fill; specifically, an increase in the weight of residual digestive

\footnotetext{
${ }^{1}$ Contribution no. 16-234-J from the Kansas Agric. Exp. Stn., Manhattan, KS 66506-0210.

${ }^{2}$ Corresponding author: Goodband@ksu.edu

Received May 27, 2016.

Accepted October 31, 2016.
}

contents in the colon and cecum. Feeding high amounts of byproducts throughout the finishing period can potentially reduce feed cost; however, this benefit could be offset if revenue is lost due to lower HCW. Thus, development of mitigation strategies to overcome the reduction in carcass yield when feeding high-fiber ingredients could prove beneficial for swine producers.

One strategy to overcome the carcass yield reduction is the removal of high-fiber diets approximately 3 wk before slaughter by reducing gut fill (Asmus et al., 2014; Graham et al., 2014). Coble (2015) determined that removal of high-fiber ingredients in finishing pigs 15 to $19 \mathrm{~d}$ before slaughter was sufficient to restore carcass yield. Still, there is interest in determining if other dietary manipulations during late finishing can improve carcass yield when high-fiber ingredients are fed. 
Adding fat has consistently been shown to improve ADG and G:F in finishing pigs, and in some experiments increase HCW and carcass yield (Smith et al., 1999; Engel et al., 2001). Recently, Davis et al. (2015) reported that adding beef tallow to a corn-soy diet or one that contained 30\% DDGS improved carcass yield when fed for the entire finishing period. However, research has yet to consider if adding fat during a withdrawal period (the last 2 to 3 wk before marketing), can overcome fiber's negative effect on carcass yield. Thus, the objective of this study was to determine if adding 5\% fat for $20 \mathrm{~d}$ before slaughter to a high-fiber diet containing 30\% DDGS would ameliorate the negative effect of on carcass yield.

\section{MATERIALS AND METHODS}

\section{General}

All experimental procedures and animal care were approved by the Kansas State University Institutional Animal Care and Use Committee. The experiment was conducted with 2 groups of pigs utilizing a total of 1,258 pigs (initially $105.7 \mathrm{~kg} \pm 0.1 \mathrm{~kg} \mathrm{BW}$ ) in a 20 -d study. Group 1 (972 pigs, PIC $337 \times 1050$; PIC, Hendersonville, $\mathrm{TN})$ was housed in a commercial research facility in southwestern Minnesota. The facility was double-curtain sided with completely slatted concrete flooring. The barn contained 48 pens $(3.05 \times 5.49 \mathrm{~m})$, with 20 to 23 pigs per pen, equipped with a 5 -hole conventional dry self-feeder (Thorp Equipment, Thorp, WI) and a cup waterer providing ad libitum access to feed and water. Group 2 (286 pigs, PIC $327 \times 1050$; PIC, Hendersonville, TN) was housed at the Kansas State University Swine Teaching and Research Center in Manhattan, KS. Pigs were housed in an enclosed environmentally regulated, mechanically ventilated barn containing 36 pens $(2.44 \mathrm{~m} \times 3.05 \mathrm{~m})$. Pens contained 7 to 8 pigs and had adjustable gates facing the alleyway which allowed $0.93 \mathrm{~m}^{2} / \mathrm{pig}$. Each pen was equipped with a cup waterer and a single-sided, dry selffeeder (Farmweld, Teutopolis, IL) with 2 eating spaces located in the fence line for ad libitum access to feed and water. Pens were located over a completely slatted concrete floor with a manure storage pit underneath $(1.20 \mathrm{~m}$ deep). Facilities for both Group 1 and 2 were equipped with a computerized feeding system (FeedPro; Feedlogic Corp., Willmar, MN) that delivered and recorded daily feed additions of specific diets to each pen.

Before the start of the experiment, pigs were fed a common diet containing 30\% DDGS (group 1 for $21 \mathrm{~d}$ and group 2 for $53 \mathrm{~d}$ ) which was of the same sources and nutrient content used in each group. On d 0 (20 d before slaughter), pens of pigs were weighed, ranked by $\mathrm{BW}$, and allotted randomly to 1 of 4 dietary treatments within BW block. Group 1 consisted of 11 pens per treatment and group 2 consisted of 9 pens per treatment for a total of 20 replications per treatment. Dietary treatments were arranged in a $2 \times 2$ factorial with 2 diet types; a low-fiber corn-soybean meal-based diet or a high fiber corn-soybean meal-based diet with $30 \%$ DDGS, and 2 levels of added fat ( 0 or 5\%; Tables 1 and 2 ). Beef tallow served as the fat source for group 1 and choice white grease served as the added fat source for group 2. All diets were fed in meal form and balanced on a standardized ileal digestible (SID) Lys:NE ratio to be above the estimated requirements (NRC, 2012), but not balanced for energy. Diets were also formulated to be above requirements for AA based on previous research in these facilities.

Samples of the DDGS were obtained at the time of diet manufacturing. Samples of each treatment diet were obtained by collecting samples $2 \mathrm{~d}$ after initiating and $2 \mathrm{~d}$ before completing the experiment. Samples were combined for a composite sample of each treatment diet, and DDGS, and analyzed for moisture (934.01; AOAC International, 2006), CP (990.03; AOAC International, 2006), ADF and NDF (Van Soest et al., 1991), crude fiber (978.10; AOAC International, 2006), $\mathrm{Ca}$ and $\mathrm{P}$ (Campbell and Plank, 1991), ether extract (920.39 A; AOAC International, 2006), and ash (942.05; AOAC International, 2006) at a commercial laboratory (Ward Laboratories, Inc. Kearney, NE; Tables 3 and 4). Bulk density (mass per unit vol, g/L) was also measured for the complete feed with a grain density cup (Seedburo Model 8800; Seedburo Equipment, Chicago, IL).

Pens of pigs were weighed and feed disappearance determined on $\mathrm{d} 0$ and 20 to calculate ADG, ADFI, G:F, and ME and NE caloric efficiency. Energy values of ingredients were form the NRC (2012) for calculations of caloric efficiency. After final weights were taken on d 20, pigs were transported (group 1: $111 \mathrm{~km}$; group 2: $256 \mathrm{~km}$ ) to a commercial packing plant (group 1: JBS Swift and Company, Worthington, MN; group 2: Triumph Foods, LLC, St. Joseph, MO) for processing and data collection. Pigs in both groups were not allowed access to feed for $12 \mathrm{~h}$ before slaughter. Hot carcass weights at both plants were measured immediately after evisceration and each carcass evaluated for carcass yield, backfat depth, loin depth, and percentage lean. Carcass yield was calculated by dividing the $\mathrm{HCW}$ at the plant by the live weight at the farm before transport to the plant. Fat depth and loin depth were measured with an optical probe inserted between the third and fourth last rib (counting from the ham end of the carcass) at a distance approximately $7 \mathrm{~cm}$ from the dorsal midline. Hot carcass weight ADG was calculated by subtracting the assumed initial $\mathrm{HCW}$, determined by multiplying $\mathrm{d} 0 \mathrm{BW}$ by an assumed yield of $75 \%$, from the final $\mathrm{HCW}$, then divided 
Table 1. Composition of diets, Group 1 (as-fed basis) ${ }^{1}$

\begin{tabular}{|c|c|c|c|c|}
\hline \multirow[b]{3}{*}{ Added fat, $\%$} & \multicolumn{4}{|c|}{ Distillers dried grains with solubles, $\%$} \\
\hline & \multicolumn{2}{|c|}{0} & \multicolumn{2}{|c|}{30} \\
\hline & 0 & 5 & 0 & 5 \\
\hline \multicolumn{5}{|l|}{ Ingredient, \% } \\
\hline Corn & 84.76 & 76.88 & 66.41 & 58.87 \\
\hline Soybean meal, $46.5 \% \mathrm{CP}$ & 13.20 & 16.06 & 1.41 & 3.94 \\
\hline Distillers dried grains with solubles & - & - & 30.00 & 30.00 \\
\hline Beef tallow & - & 5.00 & - & 5.00 \\
\hline Dicalcium $\mathrm{P}, 18.5 \% \mathrm{P}$ & 0.35 & 0.35 & - & - \\
\hline Limestone & 0.92 & 0.92 & 1.18 & 1.18 \\
\hline Salt & 0.35 & 0.35 & 0.35 & 0.35 \\
\hline Vitamin premix ${ }^{2}$ & 0.05 & 0.05 & 0.05 & 0.05 \\
\hline Trace mineral premix ${ }^{3}$ & 0.05 & 0.05 & 0.05 & 0.05 \\
\hline L-Lys $\mathrm{HCl}$ & 0.23 & 0.22 & 0.45 & 0.45 \\
\hline DL-Met & 0.02 & 0.04 & - & - \\
\hline L-Thr & 0.06 & 0.06 & 0.06 & 0.07 \\
\hline L-Trp & - & - & 0.03 & 0.03 \\
\hline Phytase $^{4}$ & 0.03 & 0.03 & 0.03 & 0.03 \\
\hline Total & 100.00 & 100.00 & 100.00 & 100.00 \\
\hline \multicolumn{5}{|l|}{ Calculated analysis } \\
\hline Standardized ileal digestible (SID) Lys:NE, g/Mcal & 2.57 & 2.57 & 2.57 & 2.57 \\
\hline \multicolumn{5}{|l|}{ SID AA, $\%$} \\
\hline Lys & 0.66 & 0.71 & 0.65 & 0.70 \\
\hline Ile:Lys & 62 & 62 & 58 & 58 \\
\hline Met:Lys & 31 & 33 & 36 & 34 \\
\hline Met + Cys:Lys & 60 & 60 & 66 & 63 \\
\hline Thr:Lys & 65 & 65 & 65 & 65 \\
\hline Trp:Lys & 18 & 19 & 18 & 18 \\
\hline Val:Lys & 70 & 70 & 73 & 72 \\
\hline Total Lys, \% & 0.75 & 0.80 & 0.79 & 0.84 \\
\hline $\mathrm{ME}, \mathrm{kcal} / \mathrm{kg}$ & 3,325 & 3,545 & 3,342 & 3,563 \\
\hline $\mathrm{NE}, \mathrm{kcal} / \mathrm{kg}$ & 2,551 & 2,745 & 2,524 & 2,720 \\
\hline $\mathrm{CP}, \%$ & 12.7 & 13.4 & 14.4 & 15.0 \\
\hline $\mathrm{Ca}, \%$ & 0.47 & 0.47 & 0.46 & 0.47 \\
\hline $\mathrm{P}, \%$ & 0.38 & 0.38 & 0.36 & 0.36 \\
\hline Available P, \% & 0.25 & 0.25 & 0.30 & 0.30 \\
\hline
\end{tabular}

${ }^{1}$ Each diet was fed in meal form.

${ }^{2}$ Provided per kilogram of premix: 7054,720 IU vitamin A; 1102,300 IU vitamin D3; 35,273 IU vitamin E; 3527 mg vitamin K; 6173 mg riboflavin; 22,046 mg pantothenic acid; 39,683 mg niacin; and $24 \mathrm{mg}$ vitamin B12.

${ }^{3}$ Provided per kilogram of premix: $33.1 \mathrm{~g}$ Mn from manganese oxide, $110 \mathrm{~g}$ Fe from iron sulfate, $110 \mathrm{~g} \mathrm{Zn}$ from zinc oxide, $16.5 \mathrm{~g}$ Cu from copper sulfate, $331 \mathrm{mg}$ I from calcium iodate, and $300 \mathrm{mg}$ Se from sodium selenite.

${ }^{4}$ Optiphos 2000 (Huvepharma, Sofia, Bulgaria) provided 1251 phytase units (FTU)/kg, with a release of $0.13 \%$ available P.

by $20 \mathrm{~d}$ for the period of the experiment. Hot carcass weight $\mathrm{G}: \mathrm{F}$ was calculated by dividing $\mathrm{HCW}$ gain by feed intake over the $20 \mathrm{~d}$ experiment.

\section{Statistical Analysis}

Experimental data were analyzed in a randomized complete-block design using the PROC MIXED procedure in SAS (SAS Inst. Inc., Cary, NC) with pen serving as the experimental unit and initial BW serving as the blocking factor. Data from groups 1 and 2 were analyzed as a combined dataset with the random effect of block within group and the fixed effects of treatment, group, and treatment $\times$ group. Residual assumptions were checked using standardized diagnostics on studentized residuals. The assumptions were reasonably met. No treatment $\times$ group interactions were observed for any of the response criteria and was subsequently removed from the model. Contrasts were tested between pigs fed the corn-soy and 30\% DDGS diet, with or without added fat, and the interaction between diet type and added fat were conducted. Backfat depth, loin 
Table 2. Composition of diets, Group 2 (as-fed basis) ${ }^{1}$

\begin{tabular}{|c|c|c|c|c|}
\hline \multirow[b]{3}{*}{ Added fat, $\%$ : } & \multicolumn{4}{|c|}{ Distillers dried grains with solubles, $\%$} \\
\hline & \multicolumn{2}{|c|}{0} & \multicolumn{2}{|c|}{30} \\
\hline & 0 & 5 & 0 & 5 \\
\hline \multicolumn{5}{|l|}{ Ingredient, \% } \\
\hline Corn & 84.63 & 76.41 & 66.26 & 58.60 \\
\hline Soybean meal, $46.5 \% \mathrm{CP}$ & 13.05 & 16.30 & 1.32 & 4.00 \\
\hline Distillers dried grains with solubles & - & - & 30.00 & 30.00 \\
\hline Choice white grease & - & 5.00 & - & 5.00 \\
\hline Monocalcium P, 21\% P & 0.33 & 0.33 & - & - \\
\hline Limestone & 1.07 & 1.05 & 1.28 & 1.25 \\
\hline Salt & 0.35 & 0.35 & 0.35 & 0.35 \\
\hline Vitamin premix ${ }^{2}$ & 0.08 & 0.08 & 0.08 & 0.08 \\
\hline Trace mineral premix ${ }^{3}$ & 0.08 & 0.08 & 0.08 & 0.08 \\
\hline L-Lys $\mathrm{HCl}$ & 0.23 & 0.21 & 0.45 & 0.45 \\
\hline DL-Met & 0.03 & 0.05 & - & - \\
\hline L-Thr & 0.06 & 0.07 & 0.07 & 0.07 \\
\hline L-Trp & 0.01 & - & 0.03 & 0.03 \\
\hline Phytase $^{4}$ & 0.10 & 0.10 & 0.10 & 0.10 \\
\hline Total & 100.00 & 100.00 & 100.00 & 100.00 \\
\hline \multicolumn{5}{|l|}{ Calculated analysis } \\
\hline Standardized ileal digestible (SID) Lys:NE, g/Mcal & 2.57 & 2.57 & 2.57 & 2.57 \\
\hline \multicolumn{5}{|l|}{ SID AA, $\%$} \\
\hline Lys & 0.66 & 0.71 & 0.65 & 0.70 \\
\hline Ile:Lys & 61 & 62 & 58 & 58 \\
\hline Met:Lys & 33 & 34 & 36 & 34 \\
\hline Met + Cys:Lys & 61 & 61 & 67 & 63 \\
\hline Thr:Lys & 66 & 66 & 66 & 66 \\
\hline Trp:Lys & 19 & 19 & 19 & 19 \\
\hline Val:Lys & 70 & 70 & 73 & 73 \\
\hline Total Lys, \% & 0.75 & 0.81 & 0.79 & 0.81 \\
\hline ME, kcal/kg & 3,317 & 3,551 & 3,336 & 3,570 \\
\hline $\mathrm{NE}, \mathrm{kcal} / \mathrm{kg}$ & 2,545 & 2,750 & 2,519 & 2,728 \\
\hline $\mathrm{CP}, \%$ & 12.6 & 13.5 & 14.3 & 15.0 \\
\hline $\mathrm{Ca}, \%$ & 0.50 & 0.50 & 0.50 & 0.50 \\
\hline $\mathrm{P}, \%$ & 0.38 & 0.38 & 0.36 & 0.36 \\
\hline Available P, \% & 0.23 & 0.24 & 0.28 & 0.28 \\
\hline
\end{tabular}

${ }^{1}$ Each diet was fed in meal form.

${ }^{2}$ Provided per kilogram of premix: 4409,200 IU vitamin A; 551,150 IU vitamin D3; 17,637 IU vitamin E; 1764 mg vitamin K; 3307 mg riboflavin; $11,023 \mathrm{mg}$ pantothenic acid; $19,841 \mathrm{mg}$ niacin; and $15.4 \mathrm{mg}$ vitamin B12.

${ }^{3}$ Provided per kilogram of premix: $26.5 \mathrm{~g}$ Mn from manganese oxide, $110 \mathrm{~g}$ Fe from iron sulfate, $110 \mathrm{~g} \mathrm{Zn}$ from zinc sulfate, $11 \mathrm{~g}$ Cu from copper sulfate, $198 \mathrm{mg}$ I from calcium iodate, and $198 \mathrm{mg}$ Se from sodium selenite.

${ }^{4}$ Natuphos 600 (BASF Corporation, Florham Park, NJ) provided 1324 phytase units (FTU)/kg, with a release of $0.11 \%$ available P.

depth, and percentage carcass lean were adjusted to a common HCW for analysis. Results from the experiment were considered significant at $P \leq 0.05$ and marginally significant between $P>0.05$ and $P \leq 0.10$.

\section{RESULTS AND DISCUSSION}

\section{Diet and Ingredient Analysis}

The diets used in the experiment were formulated to a constant SID Lys:NE ratio to ensure that di- etary SID Lys concentration did not influence growth (Tables 1 and 2). The same source of DDGS was used throughout the experiment within each group of pigs. Chemical analysis of the diets confirmed the expected increases in fiber fraction and ether extract concentration when DDGS and dietary fat were added (Tables 3 and 4). When 30\% DDGS was added, NDF increased by 4.4 and $3.8 \%$ units in group 1 and 2, respectively; similar to others whom fed a high-fiber diet with $30 \%$ DDGS (Urriola and Stein, 2010). Furthermore, the analyzed values for ether extract were 4 to $5 \%$ units 
Table 3. Chemical analysis and bulk density of diets and distillers dried grains with solubles (DDGS), Group 1 (as-fed basis) $^{1}$

\begin{tabular}{|c|c|c|c|c|c|c|}
\hline \multirow[b]{3}{*}{ Item } & \multirow[b]{3}{*}{ Added fat, ${ }^{2 \%} \%$} & \multicolumn{4}{|c|}{ Distillers dried grains with solubles, $\%$} & \multirow[b]{3}{*}{ DDGS } \\
\hline & & \multicolumn{2}{|c|}{0} & \multicolumn{2}{|c|}{30} & \\
\hline & & 0 & 5 & 0 & 5 & \\
\hline$\overline{\mathrm{DM}, \%}$ & & 87.76 & 88.28 & 88.23 & 88.79 & 92.10 \\
\hline $\mathrm{CP}, \%$ & & 12.9 & 12.4 & 15.7 & 15.2 & 30.6 \\
\hline ADF, $\%$ & & 3.1 & 3.0 & 4.4 & 5.3 & 10.1 \\
\hline NDF, $\%$ & & 7.6 & 7.2 & 12.2 & 11.3 & 25.5 \\
\hline Crude fiber, $\%$ & & 1.8 & 1.8 & 2.9 & 2.9 & 8.0 \\
\hline $\mathrm{Ca}, \%$ & & 0.51 & 0.56 & 0.64 & 0.71 & 0.07 \\
\hline $\mathrm{P}, \%$ & & 0.31 & 0.35 & 0.36 & 0.39 & 0.74 \\
\hline Ether extract, \% & & 2.8 & 7.5 & 4.4 & 8.5 & 9.2 \\
\hline Ash, $\%$ & & 3.19 & 3.17 & 3.69 & 3.90 & 4.08 \\
\hline Bulk density, $g / L$ & & 644 & 631 & 611 & 600 & - \\
\hline
\end{tabular}

${ }^{1}$ Diet samples were collected from each feeder at the beginning and ending of the experiment.

${ }^{2}$ Beef tallow served as the added fat source in diets for group 1 and choice white grease for group 2.

greater in diets containing 5\% added fat than diets without added fat, verifying the correct added fat concentrations were achieved. Bulk density was decreased in diets containing DDGS compared to the low-fiber corn-soy diet, as expected (Wang et al., 2007). Similar to Asmus (2012) and Salyer et al. (2012), when fat was added to the diet, bulk density was further reduced.

\section{Growth Performance and Carcass Characteristics}

Overall, there was a marginally significant $(P=$ 0.054 ) for a DDGS $\times$ added fat interaction for ADG, whereas this interaction was significant $(P<0.05)$ for $\mathrm{G}: \mathrm{F}$ and caloric efficiency on an ME and NE basis (Table 5). Interestingly, these interactions were the result of pigs fed the diet containing 30\% DDGS having a greater improvement in ADG and G:F to added fat compared to when fat was added to the diet for pigs fed the corn-soy diet. Before d 0, when pigs were fed the common diet, ADG was $0.95 \mathrm{~kg}$ per $\mathrm{d}$, thus part of this interaction is due to the increase in ADG for pigs switched from the DDGS diet to the corn-soy diet without added fat compared with those that continued to consume the DDGS diet ( 0.99 vs. $0.93 \mathrm{~kg}$ per d). These results are not consistent with those reported by Davis et al. (2015) who fed a diet with and without $30 \%$ DDGS and 5\% beef tallow for an entire finishing period and observed no interaction between diet type and added fat for ADG or G:F. The difference between Davis et al. (2015) and our study may partly be explained by the fact that dietary treatments were applied for only the last $20 \mathrm{~d}$ before slaughter in our study whereas Davis et al. (2015) fed dietary treatments for an entire finishing period.

A possible explanation for the increase in ADG for pigs fed the corn-soy diet compared to those fed the $30 \%$ DDGS diet when fat was not added, is that when pigs are switched from a high-fiber diet to a corn-soy

Table 4. Chemical analysis and bulk density of diets and distillers dried grains with solubles (DDGS), Group 2 (as-fed basis) ${ }^{1}$

\begin{tabular}{|c|c|c|c|c|c|c|}
\hline \multirow[b]{3}{*}{ Item } & \multirow[b]{3}{*}{ And added fat, ${ }^{2} \%$} & \multicolumn{4}{|c|}{ Distillers dried grains with solubles, $\%$} & \multirow[b]{3}{*}{ DDGS } \\
\hline & & \multicolumn{2}{|c|}{0} & \multicolumn{2}{|c|}{30} & \\
\hline & & 0 & 5 & 0 & 5 & \\
\hline$\overline{\mathrm{DM}, \%}$ & & 88.91 & 89.51 & 89.70 & 90.03 & 89.95 \\
\hline $\mathrm{CP}, \%$ & & 14.5 & 15.7 & 16.6 & 17.1 & 29.7 \\
\hline $\mathrm{ADF}, \%$ & & 2.5 & 4.2 & 4.4 & 5.7 & 11.8 \\
\hline NDF, \% & & 5.5 & 8.1 & 10.2 & 10.9 & 24.1 \\
\hline Crude fiber, $\%$ & & 1.3 & 2.1 & 2.1 & 3.0 & 7.1 \\
\hline $\mathrm{Ca}, \%$ & & 0.62 & 0.63 & 0.68 & 0.63 & 0.08 \\
\hline $\mathrm{P}, \%$ & & 0.35 & 0.47 & 0.46 & 0.47 & 0.87 \\
\hline Ether extract, \% & & 2.4 & 6.9 & 3.7 & 8.7 & 6.9 \\
\hline Ash, $\%$ & & 3.64 & 3.69 & 3.96 & 3.92 & 4.17 \\
\hline Bulk density, $g / L$ & & 743 & 670 & 691 & 657 & 578 \\
\hline
\end{tabular}

${ }^{1}$ Diet samples were collected from each feeder at the beginning and ending of the experiment.

${ }^{2}$ Beef tallow served as the added fat source in diets for group 1 and choice white grease for group 2. 
Table 5. Effect of 30\% dried distillers grains with solubles (DDGS) and 5\% added fat fed $20 \mathrm{~d}$ before slaughter on growth performance of finishing pigs ${ }^{1}$

\begin{tabular}{|c|c|c|c|c|c|c|c|c|c|}
\hline \multirow[b]{3}{*}{ Item } & \multirow[b]{3}{*}{ Added fat, ${ }^{2} \%$} & \multicolumn{4}{|c|}{ Distillers dried grains with solubles, $\%$} & \multirow[b]{3}{*}{ SEM } & \multirow{2}{*}{\multicolumn{3}{|c|}{ Probability, $\mathrm{P}<$}} \\
\hline & & \multicolumn{2}{|c|}{0} & \multicolumn{2}{|c|}{30} & & & & \\
\hline & & 0 & 5 & 0 & 5 & & DDGS $\times$ Added fat & DDGS & Added fat \\
\hline \multicolumn{10}{|l|}{$\overline{\mathrm{BW}, \mathrm{kg}}$} \\
\hline $\mathrm{d} 0$ & & 105.7 & 105.6 & 105.7 & 105.6 & 0.75 & 0.982 & 0.989 & 0.880 \\
\hline $\mathrm{d} 20$ & & 125.4 & 125.8 & 124.4 & 125.8 & 0.75 & 0.338 & 0.400 & 0.135 \\
\hline \multicolumn{10}{|l|}{ d 0 to 20} \\
\hline ADG, kg & & 0.99 & 1.01 & 0.93 & 1.01 & 0.014 & 0.054 & 0.056 & 0.001 \\
\hline ADFI, kg & & 3.21 & 3.19 & 3.14 & 3.08 & 0.029 & 0.472 & 0.001 & 0.182 \\
\hline G:F & & 0.308 & 0.317 & 0.297 & 0.328 & 0.004 & 0.008 & 0.902 & 0.001 \\
\hline \multicolumn{10}{|c|}{ Caloric intake, ${ }^{3} \mathrm{Mcal} / \mathrm{d}$} \\
\hline ME & & 10.65 & 11.32 & 10.49 & 11.00 & 0.010 & 0.407 & 0.011 & 0.001 \\
\hline $\mathrm{NE}$ & & 8.17 & 8.76 & 7.92 & 8.40 & 0.076 & 0.443 & 0.001 & 0.01 \\
\hline \multicolumn{10}{|c|}{ Caloric efficiency, ${ }^{4} \mathrm{Mcal} / \mathrm{kg}$} \\
\hline ME & & 10.83 & 11.28 & 11.27 & 10.91 & 0.141 & 0.006 & 0.809 & 0.709 \\
\hline $\mathrm{NE}$ & & 8.31 & 8.74 & 8.51 & 8.34 & 0.108 & 0.007 & 0.376 & 0.232 \\
\hline
\end{tabular}

${ }^{1} 1258$ pigs (initial $105.7 \pm 0.1 \mathrm{~kg}$; Group 1 PIC $337 \times 1050$; Group 2 PIC $327 \times 1050$ ) were used in a 20-d experiment with 20 pens per treatment; Group 1 (11 pens per treatment and 20 to 23 pigs per pen) and Group 2 ( 9 pens per treatment and 7 to 8 pigs per pen).

${ }^{2}$ Beef tallow served as the added fat source in diets for group 1 and choice white grease for group 2.

${ }^{3}$ Caloric intakes were calculated by the following equation (ADFI $\times$ Mcal).

${ }^{4}$ Caloric efficiencies were calculated by the following equation $(\mathrm{ADFI} \times \mathrm{Mcal}) \div(\mathrm{ADG})$.

diet, feed intake has been shown to increase (Jacela et al., 2009; Asmus et al., 2014). Turlington (1984) reported that while the weight of feed intake per $d$ did not change, the volume of feed consumed increased when pigs were fed increasing fiber. Pigs generally consume amounts of feed based on their energy requirement, but because of the increase in bulk density and increase in gut fill with fiber, pigs may not have been able to consume enough feed to meet their energy requirement (Whittemore et al., 2001). Ellis and Augsperger (2001) suggest that pigs eat to their current or past energy requirement, which supports both the increase in feed intake for pigs switched to the corn-soy diet and that pigs may not have been consuming their required amounts of energy. Therefore, after the change in diets, pigs most likely continued to eat similar volumetric amounts of feed, but because of the increased bulk density and energy concentration of the corn-soy diet compared to a diet with $30 \%$ DDGS, the pig consumes more total $\mathrm{kg}$ of feed and energy. This theory is supported by the feed intake data as pigs fed the corn-soy diet had greater $(P=0.001)$ ADFI compared with pigs that continued to eat the diet with $30 \%$ DDGS.

As for the interaction in G:F and caloric efficiency, it's important to understand that because of the elevated dietary fiber in the diets with $30 \%$ DDGS, the protein and energy in those diets are less digestible (Degen et al., 2009; Urriola and Stein, 2010). However, potentially adding 5\% added fat, which is highly digestible, to the DDGS diet met the pig's energy requirement (Kim et al., 2013). This may explain why added fat caused more of a response in growth in the high-fiber diet compared to the low-fiber corn-soy diet, as the energy in the corn-soy diet is more digestible. Therefore, pigs consuming it were closer to their energy requirement, even without added fat.

The interaction for caloric efficiency could further be explained by pigs fed the DDGS diet consumed fewer calories $(P<0.05)$ per $\mathrm{d}$ on an ME and NE basis, but consumed more calories $(P<0.05)$ when fat was added to the diet. When adding fat to the DDGS diet, pigs consumed $8.40 \mathrm{Mcal}$ per d on an NE basis. Pigs consuming the corn-soy diet without added fat consumed 8.17 Mcal per d and 8.76 Mcal per d with added fat. The ADG was similar between both diet types when adding fat, suggesting that the energy requirement is most likely between 8.17 and $8.40 \mathrm{Mcal}$ per d. Adding DDGS to the diet also decreased bulk density and increased gut fill which limited energy intake, thus pigs were likely in an energy dependent state (Campbell and Taverner, 1988).

These results are not consistent with Asmus (2012) who did not observe greater increases in ADG or improvements in $\mathrm{G}: \mathrm{F}$ when pigs were fed $3 \%$ choice white grease in a high-fiber diet compared with those fed a low-fiber, corn-soy diet for $19 \mathrm{~d}$ before slaughter. However, their diets contained 9.5 or $19 \%$ wheat middlings in addition to a high level of DDGS. The lower addition of fat, $3 \%$ versus the current $5 \%$ also may be responsible for the lack of an interaction in Asmus (2012) compared to the current experiment because the lower level of added fat may have not sufficed to meet the pig's energy requirement; therefore, the pig 
Table 6. Effect of 30\% dried distillers grains with solubles (DDGS) and 5\% added fat fed $20 \mathrm{~d}$ before slaughter on carcass characteristics and performance of finishing pigs ${ }^{1}$

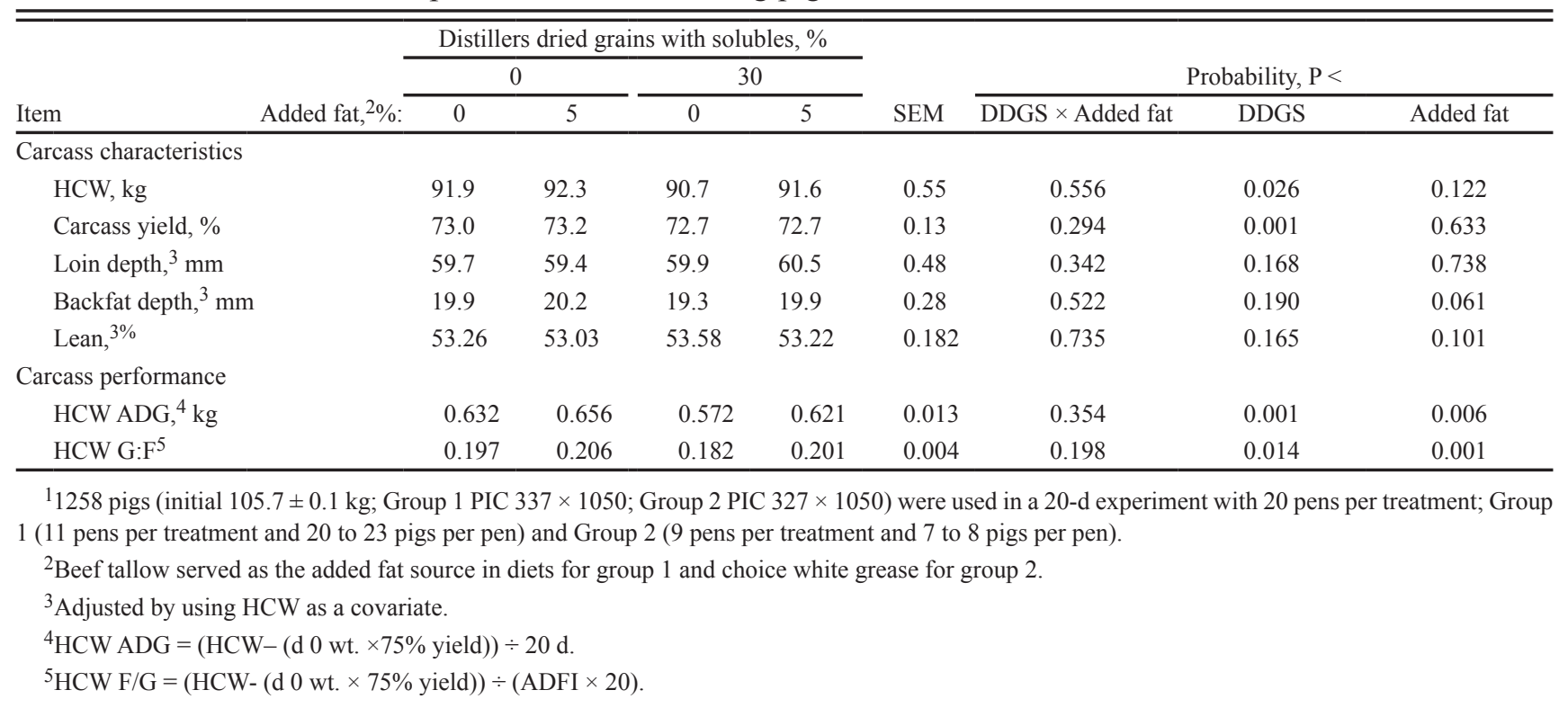

was still in an energy dependent state of growth. Also, Asmus (2012) did not balance diets on an SID Lys:NE ratio. Salyer et al. (2012) fed 20\% wheat middlings in diets containing 2.5 or $5 \%$ added choice white grease and also did not report an interaction between diet type and fat for pig performance. However, similar to Davis et al. (2015), their diets were fed for the entire finishing period; not for the last $20 \mathrm{~d}$ before slaughter. In terms of the main effect of added fat, regardless of diet type, our research is similar to others whom have reported that added fat increases ADG and improves G:F (Pettigrew and Moser, 1991; De la Llata et al., 2001; Jackson et al., 2009).

For carcass data, there were no DDGS $\times$ added fat interactions observed (Table 6). Pigs fed the DDGS diet had deceased HCW $(P=0.026)$ and percentage carcass yield $(P=0.001)$ compared with pigs fed the corn-soy diet. The reduction in carcass yield is consistent with most published literature where high-fiber diets are fed until marketing (Turlington, 1984; Whitney et al., 2006; Stewart et al., 2013). Presently, the only successful means to mitigate the reduction in carcass yield and $\mathrm{HCW}$ is to change the pigs from the high-fiber diet to a low-fiber corn-soy diet 15 to $20 \mathrm{~d}$ before slaughter (Asmus et al., 2014; Graham et al., 2014; Coble, 2015). This time period is sufficient to reduce large intestine fill associated with residual undigested fiber fractions remaining in the large intestine. Because of these results, determining the potential interaction between diet type and added fat during the last $20 \mathrm{~d}$ before slaughter was of high importance. However, added fat did not influence carcass yield.

Added fat has been shown in some cases to improve HCW and carcass yield (Smith et al., 1999; Jackson et al., 2009) while others have reported no improvements in carcass yield (Engel et al., 2001; Benz et al., 2011). Beaulieu et al. (2009) reported that for every 0.10 increase in Mcal $/ \mathrm{kg}$ of $\mathrm{DE}$, carcass yield improved by $0.20 \%$ units. However, the previous work was completed in low-fiber, cereal grain based diets and not diets containing high-fiber ingredients such as DDGS.

The lack on an interaction further suggests that adding fat to the DDGS diet does not negate the negative effect of high-fiber diets on carcass yield. Similarly, Davis et al. (2015) did not find a diet type by added fat interaction for yield when adding fat to diets containing none or $30 \%$ DDGS throughout the finishing period. Adding 3\% choice white grease to diets containing DDGS and wheat middlings (Asmus, 2012) or adding 2.5 or $5 \%$ choice white grease to diets containing $20 \%$ wheat middlings (Salyer et al., 2012) also did not improve HCW or carcass yield, even though the type and amount of fiber is different in each experiment. One explanation for added fat not being able to overcome a reduction in carcass yield in higher fiber diets, could be that added fat slows down that rate of passage and greater amounts of insoluble fiber decreases the bulk density; increasing the total vol, weight, and water holding capacity of excreta (Mateos et al., 1982; Bach-Knudsen and Hansen, 1991; Takahashi et al., 2009). The current results demonstrating the lack of benefit to fat during the withdrawal period, coupled with previous data, suggest that adding fat in short or long term periods before slaughter does not overcome the negative effect of dietary fiber on carcass yield.

Pigs fed 5\% added fat had marginally greater backfat depth $(P=0.061)$ compared with pigs not fed 
added fat, which led to a slight reduction in carcass lean. Increased carcass backfat depth is the 1 carcass trait most consistently increased with added dietary fat, due to high energy intake (Beaulieu et al., 2009; Benz et al., 2011; Salyer et al., 2012).

Because most pork producers are paid on a carcass basis in the U.S., another measurement of response to observe is carcass performance. In contrast to the live weight based calculations of feed efficiency and caloric efficiency there was no interaction in caloric efficiency based on a carcass weight basis. Pigs fed the high-fiber diet with DDGS had decreased HCW ADG $(P=$ $0.001)$ and poorer HCW G:F $(P=0.014)$ compared with those fed the low-fiber corn-soy diet. Because the DDGS diet reduced carcass yield, the amount of time required to raise a pig to a desired $\mathrm{HCW}$ is increased and the efficiency of the growth is reduced. Pigs fed added fat had increased $(P<0.05)$ HCW ADG and $\mathrm{G}:$ F compared with those not fed added fat.

In summary, adding 5\% added fat to either the diet containing 30\% DDGS or low-fiber corn-soy diet for $20 \mathrm{~d}$ before slaughter improved ADG and G:F; however, proportionally greater improvements in growth performance were observed in the high-fiber diet containing $30 \%$ DDGS. Hot carcass weight and carcass yield were reduced for pigs fed the diet with 30\% DDGS compared to those switched to the corn-soy diet, but adding 5\% fat did not influence carcass yield. Although the improvements in live and carcass performance with added fat were consistent with previous research, added dietary fat did not overcome the decreased carcass yield and HCW associated with high dietary fiber-based diets.

\section{LITERATURE CITED}

AOAC International. 2006. Official methods of analysis. 18th ed. Assoc. Off. Anal. Chem., Arlington, VA.

Asmus, M. D. 2012. Effects of dietary fiber on the growth performance, carcass characteristics, and carcass fat quality in growing-finishing pigs. MS Thesis. Kansas State University, Manhattan.

Asmus, M. D., J. M. DeRouchey, M. D. Tokach, S. S. Dritz, T. A. Houser, J. L. Nelssen, and R. D. Goodband. 2014. Effects of lowering dietary fiber before marketing on finishing pig growth performance, carcass characteristics, carcass fat quality, and intestinal weights. J. Anim. Sci. 92:119-128. doi:10.2527/jas.2013-6679

Bach-Knudsen, K. E., and I. Hansen. 1991. Gastrointestinal implications in pigs of wheat and oat fractions: 1 . Digestibility and bulking properties of polysaccharides and other major constituents. Br. J. Nutr. 65:217-232. doi:10.1079/BJN19910082

Beaulieu, A. D., N. H. Williams, and J. F. Patience. 2009. Response to dietary digestible energy concentration in growing pigs fed cereal grain-based diets. J. Anim. Sci. 87:965-976. doi:10.2527/jas.2007-0834
Benz, J. M., M. D. Tokach, S. S. Dritz, J. L. Nelssen, J. M. DeRouchey, R. C. Sulabo, and R. D. Goodband. 2011. Effects of increasing choice white grease in corn- and sorghum-based diets on growth performance, carcass characteristics and fat quality of finishing pigs. J. Anim. Sci. 89:773-782. doi:10.2527/jas.2010-3033

Campbell, C. R., and C. O. Plank. 1991. Sample Preparation. In: C. Owen Plank, editor, Plant Analysis Reference Procedures for the Southern Region of the United States. Southern Cooperative Series Bulletin \#368. p. 1-11.

Campbell, R. G. and M. R. Taverner. 1988. Genotype and sex effects on the relationship between energy intake and protein deposition in growing pigs. J. Anim. Sci. 66:676-686. doi: $10.2527 /$ jas $1988.663676 x$

Coble, K. F. 2015. Influence of dietary fiber and copper on growth performance and carcass characteristics of finishing pigs. PhD Diss. Kansas State Univ., Manhattan.

Davis, J. M., P. E. Urriola, G. C. Shurson, S. K. Baidoo, and L. J. Johnston. 2015. Effects of adding supplemental tallow to diets containing $30 \%$ distillers dried grains with solubles on growth performance, carcass characteristics, and pork fat quality in growing-finishing pigs. J. Anim. Sci. 93:266-277. doi:10.2527/jas.2014-7895

Degen, L., V. Halas, J. Tossenberger, C. Szabo, and L. Babinszky. 2009. The impact of dietary fiber and fat levels on total tract digestibility of energy and nutrients in growing pigs and its consequences for diet formulation. Acta. Agriculturae Scand. Section A. 59:150-160.

De la Llata, M., S. S. Dritz, M. D. Tokach, R. D. Goodband, J. L. Nelssen, and T. M. Loughin. 2001. Effects of dietary fat on growth performance and carcass characteristics of growingfinishing pigs reared in a commercial environment. J. Anim. Sci. 79:2643-2650. doi:10.2527/2001.79102643x

Ellis, M., and N. Augsperger. 2001. Feed intake in growing-finishing pigs. In: A.J. Lewis and L.L. Southern, editors, Swine Nutrition. 2nd ed. CRC Press, Boca Raton, FL. p. 447-467.

Engel, J. J., J. W. Smith, II, J. A. Unruh, R. D. Goodband, P. R. O'Quinn, M. D. Tokach, and J. L. Tokach. 2001. Effects of choice white grease or poultry fat on growth performance, carcass leanness, and meat quality characteristics of growing-finishing pigs. J. Anim. Sci. 79:1491-1501. doi:10.2527/2001.7961491x

Graham, A. B., R. D. Goodband, M. D. Tokach, S. S. Dritz, J. M. DeRouchey, and S. Nitikanchana. 2014. The interactive effects of high-fat, high-fiber diets and ractopamine $\mathrm{HCl}$ on finishing pig growth performance, carcass characteristics, and carcass fat quality. J. Anim. Sci. 92:4585-4597. doi:10.2527/jas.2013-7434

Jacela, J. Y., J. M. Benz, S. S. Dritz, M. D. Tokach, J. M. DeRouchey, R. D. Goodband, J. L. Nelssen, and K. J. Prusa. 2009. Effect of dried distillers grains with solubles withdrawal regimens on finishing pig performance and carcass characteristics. In: Proc. Swine Day, Stn. Rep. Prog. 1020, Manhattan, KS. p. 181-191.

Jackson, A. R., S. Powell, S. L. Johnston, J. O. Matthews, T. D. Bidner, F. R. Valdez, and L. L. Southern. 2009. The effect of chromium as chromium propionate on growth performance, carcass characteristics, meat quality, and the fatty acid profile of fat from pigs fed no supplemented dietary fat, choice white grease, or tallow. J. Anim. Sci. 87:4032-4041. doi:10.2527/jas.2009-2168

Kim, B. G., D. Y. Kil, and H. H. Stein. 2013. In: growing pigs, the true ileal and total tract digestibility of acid hydrolyzed ether extract in extracted corn oil is greater than in intact sources of corn oil or soybean bean oil. J. Anim. Sci. 91:755-763. doi: 10.2527/jas.2011-4777

Mateos, G. G., J. L. Sell, and J. A. Eastwood. 1982. Rate of food passage (transit time) as influenced by level of supplemental fat. Poult. Sci. 61(1):94-100. doi:10.3382/ps.0610094 
NRC. 2012. Nutrient Requirements of Swine. 11th rev. ed. Natl. Acad. Press, Washington, DC.

Pettigrew, J. E., and R. L. Moser. 1991. Fat in swine nutrition. In: E. R. Miller, D. E. Ullrey, and A. J. Lewis, Editors, Swine Nutrition. 1st ed. Butterwirth-Heinemann, Stoneham, MA. p. 133-145.

Salyer, J. A., J. M. DeRouchey, M. D. Tokach, S. S. Dritz, R. D. Goodband, J. L. Nelssen, and D. B. Petry. 2012. Effects of dietary wheat middlings, distillers dried grains with solubles, and choice white grease on growth performance, carcass characteristics, and carcass fat quality of finishing pigs. J. Anim. Sci. 90:2620-2630. doi:10.2527/jas.2011-4472

Smith, J. W., II, M. D. Tokach, P. R. O'Quinn, J. L. Nelssen, and R. D. Goodband. 1999. Effects of dietary energy density and lysine:calorie ratio on growth performance and carcass characteristics of growing-finishing pigs. J. Anim. Sci. 77:30073015. doi:10.2527/1999.77113007x

Stewart, L. L., D. Y. Kil, F. Ji, R. B. Hinson, A. D. Beaulieu, G. L. Allee, J. F. Patience, J. E. Pettigrew, and H. H. Stein. 2013. Effects of dietary soybean hulls and wheat middlings on body composition, nutrient and energy retention and the net energy of diets and ingredients fed to growing and finishing pigs. J. Anim. Sci. 91:2756-2765. doi:10.2527/jas.2012-5147

Takahashi, T., Y. Furuichi, T. Mizuno, M. Kato, A. Tabara, Y. Kawanda, Y. Hirano, K. Kubo, M. Onuzuka, and O. Kurita. 2009. Waterholding capacity of insoluble fibre decreases free water and elevates digesta viscosity in the rat. J. Sci. Food Agric. 89:245-250. doi:10.1002/jsfa.3433
Turlington, W. H. 1984. Interactive effects of dietary fiber levels and environmental temperature on growing pigs. MS Thesis. University of Kentucky., Lexington.

Urriola, P. E., and H. H. Stein. 2010. Effects of distillers dried grains with solubles on amino acid, energy, and fiber digestibility and on hindgut fermentation of dietary fiber in a corn-soybean meal diet fed to growing pigs. J. Anim. Sci. 88:1454-1462. doi:10.2527/jas.2009-2162

Van Soest, P. J., J. B. Robertson, and B. A. Lewis 1991. Methods for dietary fiber, neutral detergent fiber, and nonstarch polysaccharides in relation to animal nutrition. J. Dairy Sci. 74:3583-3597. doi:10:3168/jds.S0022-0302(91)78551-2

Wang, Z., S. Cerrate, C. Coto, F. Yan, and P. W. Waldroup. 2007. Use of constant or increasing levels levels of distillers dried grains with solubles (DDGS) in broiler diets. Int. J. Poult. Sci. 6(7):501-507. doi:10.3923/ijps.2007.501.507

Whitney, M. H., G. C. Shurson, L. J. Johnston, D. M. Wulf, and B. C. Shanks. 2006. Growth performance and carcass characteristics of grower-finisher pigs fed high-quality corn distillers dried grain with solubles originating from a modern Midwestern ethanol plant. J. Anim. Sci. 84:3356-3363. doi:10.2527/jas.2006-099

Whittemore, C. T., D. M. Green, and P. W. Knap. 2001. Technical review of the energy and protein requirements of growing pigs: Food intake: Food intake. Anim. Sci. 73:3-17. doi:10.1017 S1357729800058008 